\title{
Nurses Perception of their Work Environment at a Referral Hospital in Western Kenya
}

\author{
Alex Chebor ${ }^{1} *$, Kennedy Simiyu ${ }^{2}$, Titus Tarus ${ }^{2}$, Judith Mangeni ${ }^{3}$ and \\ Millicent Obel $^{3}$ \\ ${ }^{1}$ University of Kabianga, P.O BOX 2030-20200 Kericho, Kenya. \\ ${ }^{2}$ Moi Teaching and Referral P.O BOX 3-30100 Eldoret, Kenya. \\ ${ }^{3}$ Moi University P.O BOX 4606-30100 Eldoret, Kenya.
}

\begin{abstract}
The nursing practice environment has been defined as the organizational characteristics of a work setting that facilitate or constrain professional nursing practice. ${ }^{5}$. Examples of these characteristics include the nature of nurses' relationships with managers and physicians, and the status of nurses within the hospital hierarchy.

The purpose of this study was to assess the nurses' perception of the work environment and the subsequent work morale using the Practice Environment Scale of the Nursing Work Index (NWI-R).Specific Objectives: 1).To determine the nurses' work morale at the Moi teaching and referral hospital. 2). To determine the nursephysician relationship levels at the Moi teaching and referral hospital. We used a cross-sectional study design with consecutive sampling. Data was collected from 167 nurses working in various units in the month of August 2013. Analysis was done using the SPSS version 18.0, item total of all the five scales of the NWI-R factor analysis was done whereby the subscale mean scores were obtained. Qualitative responses were grouped according to similarities of phrases used to the NWI-R scales. These phrases were then used in the discussion.

Of those interviewed, males were 29 and females138. Majority of the nurses (53\%) had a feeling that they are not in control of their own practice. One third (32\%) felt they rarely participate in policy decisions for the hospital. With regard to staffing, 55.7\% agreed with the presence of adequate support services that allow them time to spend with their patients.

Most of the nurses do not agree (means below 2.5) that they participate in hospital affairs, that there is nursing foundations for quality care that there is adequate staffing and resources and lastly that there is collegial relationship between them and physicians. It is only on the nurse manager ability, leadership and support that they seem to agree (mean of 2.8).

Based on this study it is evident there is low morale among the nursing staff at the Referral Hospital (NWI-R score of below 2.5). The working relationship between nurses and physicians is poor (NWI-R score of below 2.5)

There is need to engage nurses in morale boosting activities like refresher courses, recognition of a job well done, and engaging them more often in decision making activities in the hospital.
\end{abstract}

Key words: Nurse, Work-environment, Morale, Interpersonal Relationships, public hospital

\section{Introduction}

Amid the advent of a national nursing shortage in the early 1990s, Kenyan public and private hospitals had problems attracting or retaining professional nursing staff. Conversely the American and other developed countries' hospitals had fewer problems attracting or retaining professional nursing staff due to their labeled "magnet" hospital statuses. These "magnet" hospitals, reputed by local and expatriate nurses to be good places to work, were the focus of a study by the American Academy of Nursing (AAN) to determine the organizational characteristics that accounted for nurse satisfaction and retention ${ }^{1,2}$. Through interviews with nurse executives and staff nurses in 41 such hospitals, researchers found many characteristics that were common to these "magnetic" organizations. In addition to comparatively low nurse turnover rates, these institutions were characterized by their staff nurses as having adequate staffing levels; flexible scheduling; strong, supportive, and visible nurse leadership; recognition for excellence in practice; participative management with open communication; good relationships with physicians; salaried rather than hourly compensation for nurses, professional development; and career advancement opportunities ${ }^{9}$. These institutions also were found to have a somewhat richer nursing skill mix, reflecting the high priority they placed on quality patient care.

Transitions in world wide health care provision have however sparked public and professional concern regarding the status of inpatient hospital nursing and its effect on the quality of care in hospitals, prompting inquiries into this issue of nurses and their work environment. Much work needs to be accomplished in the area of measuring patient and nursing outcomes of organizational change. Research that examines the environment 
or context of care is necessary, specifically studies on how the environment in which nurses practice affects the results of care. It has been well documented that the work environment affects nurse satisfaction and turnover ${ }^{9}$, which in turn influences the organizational cost of replacing nurses ${ }^{\mathbf{1 0}}$.

Professional practice environments support nurses to function at the highest scope of clinical practice, to work effectively in an interdisciplinary team of caregivers, and to mobilize resources quickly. Through these mechanisms, professional practice environments contribute to better quality of care. Better quality of care, in turn, leads to superior health care outcomes ${ }^{1}$.

In hospital settings, Nurses maintain and manage the environment surrounding the delivery of care, which has increasingly involved coordinating the care activities provided by other health care providers. Hence, improvements in nurses' practice environments are essential to retain nurses and keep patients safe. The pace of improvements can accelerate if evidence is translated clearly for researchers, managers, and policymakers in both hospital set-ups and the ministry of health.

The relationship between nursing morale, quality care, patient care environments and patient outcomes has long been established ${ }^{4}$. Researchers ${ }^{4}$ have found that hospitals with better patient outcomes are characterized by organizational cultures, which foster good relationships between doctors and nurses, and a perception of autonomy and control of their own practice on the part of nurses. Positive care environments that include adequate staffing, education, and relationships have also been found to be significantly associated with decreased mortality ${ }^{2,3}$.

While it seems logical to assume that safe and effective patient care depends on the presence of an organizational context that enables the best performance from each health professional, remarkably little knowledge has accumulated about how the organization and delivery of nursing services influences patient outcomes. The current study therefore sought to assess the nurses' perceptions of the practice environment with emphasis to their work morale and interpersonal relationships with physicians at a large Referral Hospital with the aim of improving the patient care outcomes in that hospital.

\section{Methods}

Setting: The target population for this study was nurses working at various units within the hospital. The hospital has a total nursing population of 750 and 200 medical practitioners.

Participants: Nurses, who had worked in the hospital for at least 2yearswere eligible to participate. A total of 167 nurses (all the nurses who were eligible and were on duty) participated in the study done in the month of August, 2013.

Design: Cross-sectional study design was used in the study, whereby the participants were conveniently sampled and handed questionnaires for filling.

Data collection: Data collection in the various units of the hospital was done in the month of August, 2013.

The Nursing Work Index revised (NWI-R) adopted from Linda H Aiken combined with the nurses' socialdemographics was used.

NWI-R measures the extent to which a nurse's work setting facilitates professional nursing practice as exemplified by the original magnet hospitals ${ }^{5}$. The NWI-R has been shown to be a valid and reliable tool for the measurement of the hospital nursing practice environment. It comprises subscales of from three to ten items each. The nurse rates each item on a scale of 1 (strongly disagree) to 4 (strongly agree) to indicate whether the feature is "present in the current job." The subscales describe the nature of professional nursing practice in the original magnet hospitals: Nurse Participation in Hospital Affairs; Staffing and Resource Adequacy; Nursing Foundations for Quality of Care; Nurse Manager Ability, Leadership, and Support of Nurses; and Collegial Nurse/Physician Relations.

The subscale score is the average of the subscale item responses. A single "composite" score is calculated as the mean of the subscale scores. The potential score range is 1 through 4 . Higher scores indicate more agreement that the subscale items are present in the current job situation. Values above 2.5 indicate agreement; values below 2.5 indicate disagreement.

An additional open ended question on the nurses' thoughts on their work environment was used to collect further information for discussion.

\section{Ethical considerations:}

Before the commencement of the study, approval was sought from the institutional research and ethics committee (IREC). The participants were informed both in oral and written about the purpose of the study. The participation was voluntary, and one could withdraw at any given point without fear of reprimand. Confidentiality was ensured.

Data analysis: Data was analyzed, using the SPSS version 18.0. Cross tabulations and mean scores of item total of the five sub scales were obtained. 
Qualitative responses from the additional open-ended question were analyzed through thematic content analysis that in essence bore similar subscales of the NWI-R, though with much specificity to the particular hospital. The responses to the open ended question were written down for each respondent during the data entry exercise. These responses were then grouped into phrases with reflective themes of the Nursing Work Index (NWI-R) and similar wording excerpts used in the discussion of the article.

\section{Demographic Data}

\section{Results}

A total of 167 nurses were interviewed, out of which males were 29 and females138. Among them 14 had degrees as the highest educational level, 125 had diploma and 38 were trained up to certificate level.

The respondents had a practicing mean of 6.3 years in the hospital and a mean of 9.3 years in practice as a nurse since qualifying from college.

Table 1: Age Distribution

\begin{tabular}{|l|l|l|}
\hline Age & Frequency & Percent \\
\hline $21-30$ & 53 & 32.7 \\
\hline $31-40$ & 63 & 38.9 \\
\hline $41-50$ & 32 & 19.8 \\
\hline $51-55$ & 11 & 6.8 \\
\hline$>55$ & 3 & 1.9 \\
\hline Total & 162 & 100.0 \\
\hline
\end{tabular}

Table 2: Departmental distribution.

\begin{tabular}{|l|l|l|}
\hline & Frequency & Percent \\
\hline Medicine & 15 & 10.0 \\
\hline Pediatric & 25 & 16.7 \\
\hline Surgery & 42 & 28.0 \\
\hline reproductive health & 25 & 16.7 \\
\hline Renal & 8 & 5.3 \\
\hline consultants clinics & 7 & 4.7 \\
\hline ICU & 8 & 5.3 \\
\hline Diagnostic & 4 & 2.7 \\
\hline Dental & 2 & 1.3 \\
\hline AE & 14 & 9.3 \\
\hline Total & 150 & 100.0 \\
\hline
\end{tabular}

The findings were classified into two major categories, namely;

A. Nurse morale in the delivery of patient care.

B. Interpersonal relationship between nurses and physicians.

A. Assessment of nurses' morale

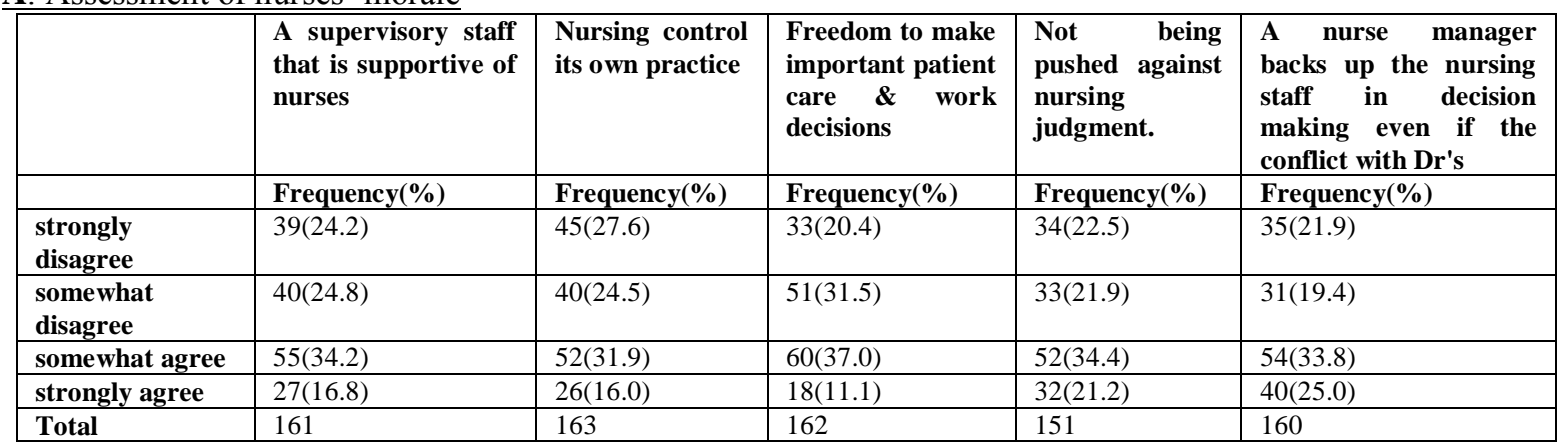

\section{Autonomy}

With reference to autonomy of the nursing profession, most of the nurses (53\%), have a feeling that they are not in control of their own practice. It is also evident that nurses rarely (32\%) participate in policy decisions for the hospital.

About $63 \%$ of nurses surveyed agreed that there is support for new and innovative ideas about patient care while $56 \%$ disagreed on if there is enough time and opportunity to discuss patient care problems with other health care providers as shown in the table above.

\section{Staffing subscale}

With reference to staffing, $55.7 \%$ agreed with the presence of adequate support services that allow them time to spend with their patients while $44.3 \%$ did not agree. About career development and opportunity for 
nurses to participate in policy decisions regarding patient care, $67.5 \%$ and $68.9 \%$ respectively disagreed on the presence of these opportunities while the rest of the percentages (32.5\% and $31.1 \%$ respectively) agreed.

\section{Motivation/Recognition subscale}

On regard to motivation subscale, $49 \%$ versus $51 \%$ disagreed that there is a supportive supervisory staff whereas all the nurses unanimously agreed $(77.2 \%)$ that there is no recognition for a job well done. Opportunities for job promotion were also reportedly $(81.7 \%)$ not readily available to the nurses and the administration was evaluated as not responsive to the nurses concerns. However, they could not agree (50.6\%) or disagree $(49.4 \%)$ on whether the working environment was pleasant, attractive and comfortable.

\section{B. Interpersonal relationship issues between nurses and physician}

\section{Collegial Nurse/Physician Relations sub-scale}

\begin{tabular}{|l|l|l|l|}
\hline & Physician/nurse relationship & Team work between nurse \& Dr. & $\begin{array}{l}\text { Collaboration between nurse } \\
\text { and physician }\end{array}$ \\
\hline & Frequency (\%) & Frequency (\%) & Frequency (\%) \\
\hline $\begin{array}{l}\text { strongly } \\
\text { disagree }\end{array}$ & $12(7.3)$ & $13(8.1)$ & $22(13.8)$ \\
\hline $\begin{array}{l}\text { somewhat } \\
\text { disagree }\end{array}$ & $23(14.0)$ & $27(16.8)$ & $38(23.9)$ \\
\hline $\begin{array}{l}\text { somewhat } \\
\text { agree }\end{array}$ & $82(50.0)$ & $77(47.8)$ & $65(40.9)$ \\
\hline $\begin{array}{l}\text { strongly } \\
\text { agree }\end{array}$ & $47(28.7)$ & $44(27.3)$ & $34(21.4)$ \\
\hline Total & 164 & 161 & 159 \\
\hline
\end{tabular}

When asked about their relationship with doctors or any other clinicians, $79 \%$ somewhat agreed the responses to team work between nurses and doctors $(75.1 \%)$ as well as collaboration between nurse and physician $(62.3 \%)$ in patient care as shown in table(2) above.

Table 3: The subscale mean scores

\begin{tabular}{|l|l|l|l|l|l|}
\hline The NWI-R subscales & Interrelationship subscale \\
\hline & \multicolumn{3}{|l|}{ Morale subscales } \\
\cline { 2 - 6 } & $\begin{array}{l}\text { nurse participation } \\
\text { in hospital affairs } \\
\text { mean score }\end{array}$ & $\begin{array}{l}\text { nursing foundations } \\
\text { for quality of care } \\
\text { mean score }\end{array}$ & $\begin{array}{l}\text { nurse manager } \\
\text { ability, leadership, } \\
\text { and support of nurses } \\
\text { mean score }\end{array}$ & $\begin{array}{l}\text { staffing and } \\
\text { resource } \\
\text { adequacy } \\
\text { mean score }\end{array}$ & $\begin{array}{l}\text { collegial nurse-physician } \\
\text { relationship mean score }\end{array}$ \\
\hline Mean & $\mathbf{2 . 4 3 2 5}$ & $\mathbf{2 . 4 3 5 0}$ & $\mathbf{2 . 8 1 7 5}$ ) & $\mathbf{1 . 9 9 8 3}$ & $\mathbf{2 . 4 0 0 9}$ \\
\hline Std. Deviation & .56572 & .55189 & $\mathbf{. 6 2 9 8 8}$ & .70680 & .63169 \\
\hline Range & 2.67 & 3.00 & $\mathbf{2 . 6 0}$ & 3.00 & 3.00 \\
\hline
\end{tabular}

From the above table (table 3), it is apparent that most of the nurses do not agree (means below 2.5) that they participate in hospital affairs, that there is nursing foundations for quality care, that there is adequate staffing and resources and lastly that there is collegial relationship between them and physicians. It is only on the nurse manager ability, leadership and support that they firmly agreed (mean of 2.8), of their leadership capabilities.

Further, an open-ended question asking for the nurses' additional thoughts on the hospital work environment that they felt could share was added on the NWI-R. Several pertinent issues specific to the hospital were realized from this question. The lack of nursing space (congestion of patients in wards), lack of promotion, recognition of the nurses' work by other health care givers, the nurse patient ratios and re-structuring of the working shifts of the nurses as well as training opportunities accorded to the nurses were depicted by the respondents as the main factors that make up a good working environment for nurses.

\section{Discussion}

A professional nurse practice environment is a system that supports registered nurse control over the delivery of nursing care and the environment in which care is delivered, such an environment is one that empowers nurses by providing them with increased opportunities for autonomy, accountability, and control over the environment in which they deliver care ${ }^{10}$.

The NWI-R performs well in identifying manipulatable aspects of organizations important to good patient outcomes. It has been shown that nurses are appropriate informants of the organizational features important in clinical care ${ }^{1}$. Issues that have been identified as an explanation for poor morale among nurses, and their relationship with physicians in management of patients have been found to be part of the factors that affect the smooth delivery of nursing care. These factors include nurses' professional autonomy (worth/ respect), opportunity/skill development, adequacy in staffing, participation in hospital affairs, motivation and leadership. In the current study, nurses' felt that most of their training needs at the hospital were not met, in that very few 
were being sponsored for professional training and most having been denied opportunities for further education. One of the respondents reiterated "tell me of any nurse whose master's education has been paid for by the hospital and I will name a lot of young physicians we have trained by the hospital funds". Some respondents felt that the nursing management was not fully incorporated in the hospital decision making and often decisions by the hospital are undermining on the nurses' welfare, with most(68.9\%) siting the working shifts that did not recognize the uniqueness of nursing care, leaving them as the most heavily burdened group of workers in the hospital and $81.7 \%$ reporting lack of promotion of nurses as non-responsiveness of the administration to nursing issues.

It is noteworthy that while there has been evidence of low morale among nurses and poor relationships with physicians, most of the studies have been largely confined to the developed countries ${ }^{1}$. Such studies therefore are desirable in the developing countries like Kenyain order to improve the outcome of patient care.

The current study reveals that the nurses' morale in the Referral hospital is low as evidenced by the low mean scores of less than 2.5, a finding which is consistent with other studies in south Africa and other parts of the world like Australia and United States of America ${ }^{8}$. The studies, further identified low morale as being costly to organizations and a key source of poor patient outcomes and care. Understanding the impact of organizational traits on the morale of nurses allows managers to develop appropriate workplace strategies.

When nurses are given authority in line with their responsibility, autonomy, and control over patient care resources, they are in a better position to establish positive relationships with physicians. In addition, nurses functioning in such an environment can apply resources as appropriate for best meeting patients' needs and for communicating problems to the physician in a timely manner. Theoretically, these environmental factors are responsible for better patient, nurse, and organizational outcomes ${ }^{9}$.

It has been well documented that the work environment affects nurse satisfaction and turnover ${ }^{9}$, which in turn influences the organizational cost of replacing nurses. ${ }^{10}$ Moreover, several studies have established a link between satisfied nurses, satisfied patients, and better quality of care $e^{2,4,8}$.

Nurses interviewed reported, inadequacy of nurses in the ward areas, therefore increased workload. "Lack of nursing space" to mean high patient numbers in the ward with squeezed nurse stations and inappropriate "nurse-patient ratios" in the hospital, werealso commonly cited by the nursesas impediments to daily nursing care activities in the hospital. It's however noteworthy thatnursing shortage is not affecting only nurses. Services have been reduced, surgeries canceled, and units closed in many other facilities ${ }^{11}$. Consequently, patient satisfaction has decreased, quality of care and patient safety in most health facilities have been compromised, and the rate of medical errors risen. ${ }^{12}$ Therefore, the nursing shortage has become one of the most pressing concerns for hospitals nationwide and the ministry of health in Kenya.

Further, most nurses $(63 \%)$ when asked to share their thoughts on the nursing environment reported increased workload due to the demand for quality care from the hospital nursing management and increasing awareness of the patients/clients on their rights and expectations while admitted.A phenomenon reflected in all level 4 and above hospitals in Kenya. A similar number of nurses returned overwhelming responses, indicating lack of autonomy of the nursing fraternity from the physicians in the hospital as affecting favorable decision makingin nursing care.

The perception of nurses as regards to leadership, autonomy and their professional interrelationship with doctors is poor as evidenced by the low collegial nurse-physician relationship subscale mean score of 2.4 in the current study. This has in turn affected the delivery of care negatively in the hospital, a finding consistent with Aiken's 2003 work $^{7}$. Consequently, Nurse Managers may implement well-planned structures,policies, and systems; they may implement superb shared governancecouncil structures, but unless nurses confirm these implementations as functional, and are willing to be part and parcel of it, desired patient and nurse outcomesmay not be realized.

Further, review of literature also demonstrates that there are obvious areas for future exploration that have an impact upon structural, theoretical and work setting elements of nursing and morale.

\section{Conclusion}

In conclusion, nurses' morale and their relationship with physicians, is critical in changing and improving nurse job satisfaction and hence create hospital environments that attract and retain qualified nurses, as well as improving patient care. It is evident in the current study that there is low morale among the nursing staff within the hospital (NWI-R score of below 2.5) as well as poor working relationship between nurses and physicians (NWI-R score of below 2.5).

\section{Recommendations}

There is need to engage nurses in morale boosting activities like refresher courses, recognition of a job well done, and engaging them more often in decision making activities in the hospital. 
Clear cut, role assignment by the institution to nurses and doctors, to avoid interpersonal conflicts on the work place. Further team building activities aimed at improving work relationships between the two professions be regularly organized.

\section{Competing interests}

The author(s) declare that they have no competing interests.

\section{Authors' contributions}

This topic was conceived and designed by Titus K.T, Judith N.M, Kennedy N.S and Alex K.C.Alex K.Cand Kennedy N.S contributed in the designing and data collection process as well as analysis. Kennedy N S and Alex KC translated the questionnaire from English to Kiswahili and back. Kennedy S. and Alex C. drafted the paper.

\section{Acknowledgements}

The authors acknowledge the contributions made bythe hospital management, Prof Angela A, Jane N and Brian $\mathrm{K}$. Many thanks also goes to the public relations officers, clinicians, nurses and patients for their cooperation during the data collection process.

\section{References:}

[1]. Aiken, L.H., P.A. Patrician. 2000. Measuring Organizational Traits of Hospitals: The Revised Nursing Work Index. Nursing Research 49: 146-153.

[2]. Aiken, L.H., S. P. Clarke, and D.M. Sloane, et al. 2009. Effects of Hospital Care Environment on Patient Mortality and Nurse Outcomes.JONA 39:s45-51

[3]. Aiken, L.H., S. P. Clarke, and D.M. Sloane, et al. 2002. Hospital Nurse Staffing and Patient Mortality, Nurse Burnout, and Job Dissatisfaction.JAMA 288(16): 1987-93

[4]. Aiken, L. H., H. L. Smith, and E. T. Lake. 1994. Lower Medicare Mortality among a Set of Hospitals Known for Good Nursing Care. Medical Care 32: 771-787.

[5]. Lake E. Development of the Practice Environment Scale of the Nursing Work Index. Research in Nursing and Health.2002;25(3):176-88

[6]. Porter-O'Grady T, George V. A mature shared governance system: more structure than substance. J Nurs Adm. 1996; 26(2):14-20.

[7]. Aiken L, Clarke S, Cheung R, Sloane D, Silber J. Education Levels of Hospital Nurses and Patient Mortality. Journal of the American Medical Association.2003;290(12):1617-23.

[8]. Penn-Kekana, Loveday, Duane Blaauw, Khin San Tint,DesireeMonareng, and Jane Chege. 2005. Nursing Staff Dynamics and Implications for Maternal Health Provision in Public Health Facilities in the Context of HIV/AIDS.Washington,DC:PopulationCouncil. (http://www.popcouncil.org/pdfs/factsheets/RH_LowMoraleSANurses_A4.pdf )

[9]. Lake, E. (1998) Advances in understanding and predicting nurse turnover. Research in the Sociology of Health Care, 15, 147-171.

[10]. Zelauskas, B., \&Howes, D. G. (1992). The effects of implementing a professional practice model. Journal of Nursing Administration, 22(7/8), 18-23.

[11]. Fackelmann K. Nursing shortage imperils patients. USA Today 2001 June 27; 1D

[12]. Houle J. Nursing World Health \& Safety Survey. Washington (DC): American Nurses Association; 2001 Sept. http://nursingworld.org/surveys/hssurvey.pdf 